\title{
Mechanisms underlying HIV-1 Vpu-mediated viral egress
}

\author{
Nicolas Roy ${ }^{1,2,3}{ }^{\dagger}$, Grégory Pacini ${ }^{1,2,3}{ }^{\dagger}$, Clarisse Berlioz-Torrent ${ }^{1,2,3}$ and Katy Janvier ${ }^{1,2,3}$ * \\ 1 INSERM U1016, Institut Cochin, Paris, France \\ ${ }^{2}$ CNRS UMR8104, Paris, France \\ ${ }^{3}$ Université Paris Descartes, Paris, France
}

\section{Edited by:}

Nadine Laguette, Centre National de la Recherche Scientifique, France

\section{Reviewed by:}

Kenzo Tokunaga, National Institute of Infectious Diseases, Japan

Clare Lisa Jolly, University College

London, UK

\section{*Correspondence:}

Katy Janvier, INSERM U1016, Institut

Cochin, 27, Rue du Faubourg Saint

Jacques, Bat. Gustave Roussy-6th

Floor, 75014 Paris, France

e-mail: katy.janvier@inserm.fr

${ }^{\dagger}$ Nicolas Roy and Grégory Pacini have

contributed equally to this work.
Viruses such as lentiviruses that are responsible for long lasting infections have to evade several levels of cellular immune mechanisms to persist and efficiently disseminate in the host. Over the past decades, much evidence has emerged regarding the major role of accessory proteins of primate lentiviruses, human immunodeficiency virus and simian immunodeficiency virus, in viral evasion from the host immune defense. This short review will provide an overview of the mechanism whereby the accessory protein Vpu contributes to this escape. Vpu is a multifunctional protein that was shown to contribute to viral egress by down-regulating several mediators of the immune system such as CD4, CD1d, NTB$A$ and the restriction factor BST2. The mechanisms underlying its activity are not fully characterized but rely on its ability to interfere with the host machinery regulating protein turnover and vesicular trafficking. This review will focus on our current understanding of the mechanisms whereby Vpu down-regulates CD4 and BST2 expression levels to favor viral egress.

Keywords: Vpu, CD4, BST2/Tetherin, HIV-1, ESCRT, degradation, cell surface down-regulation, NF-KB

\section{INTRODUCTION}

Viral egress and replication rely on a complex interplay between viral and cellular proteins. During their replication cycle, viruses, notably lentiviruses, have to face several levels of the host immune defense mechanisms and must counteract these barriers to persist and disseminate in the host. Understanding the mechanisms underlying lentiviruses evasion from host antiviral activities has been the focus of many studies of the past decades. Not only did they contribute to major advances in the characterization of host strategies to repress viral replication, notably by the identification of antiviral cellular proteins such as APOBEC3G, SAMHD1, TRIM5 $\alpha$, and BST2 referred to as restriction factors (Sheehy et al., 2002; Stremlau et al., 2004; Neil etal., 2008; Van Damme et al., 2008; Laguette et al., 2011), but also they unraveled the importance of the accessory proteins of viruses in this process (Malim and Bieniasz, 2012).

The genome of lentiviruses encodes for several accessory proteins such as Nef, Vif, Vpr, Vpx, and Vpu, in addition to the structural and enzymatic proteins Gag, Pol, and Env and the regulatory proteins Tat and Rev (Malim and Bieniasz, 2012). These accessory proteins are, however, not common to all lentiviruses: Nef and Vpr are specific of primate lentiviruses (HIV-1, HIV-2, and SIV), Vpx is expressed by HIV-2 and its closely related $\mathrm{SIV}_{\mathrm{smm}}$ and $\mathrm{SIV}_{\mathrm{mac}}, \mathrm{Vpu}$ is expressed by HIV-1 strains and a few strains of SIV (described later; Malim and Emerman, 2008). These proteins are not strictly required for viral replication in vitro. However, much evidence has highlighted their importance in the pathogenesis of the infection, as they contribute to modify the cell environment to facilitate viral replication and evasion from the host antiviral immune response (Malim and Emerman, 2008).

This review will provide an overview of our current understanding of the mechanisms whereby the accessory protein Vpu exploits the host cell machineries to counteract two components of the adaptive and innate host immune system: the protein CD4 and the restriction factor BST2.

\section{CHARACTERISTICS AND FUNCTIONS OF THE ACCESSORY PROTEIN VPU}

The accessory protein $\mathrm{Vpu}$ is an 81-amino acid type I integral membrane phosphoprotein, expressed by the genome of HIV-1, the related $\operatorname{SIV}_{\mathrm{cpz}}$ (Strebel et al., 1988) and the $\mathrm{SIV}_{\mathrm{gsn}}$ lineages including the greater spot-nosed monkey $\left(\mathrm{SIV}_{\mathrm{gsn}}\right)$, the mona monkey $\left(\operatorname{SIV}_{\text {mon }}\right)$, the mustached monkey ( $\left.\operatorname{SIV}_{\text {mus }}\right)$ and Dent's mona monkey $\left(\mathrm{SIV}_{\mathrm{den}}\right)$ isolates (Gao et al., 1999; Courgnaud et al., 2002, 2003; Bailes et al., 2003). Vpu contains a short luminal $\mathrm{N}$-terminal domain, a 23-amino acid transmembrane domain and a large cytoplasmic C-terminal domain (Strebel et al., 1988; Maldarelli et al., 1993). Vpu localizes mainly in the endoplasmic reticulum (ER), the trans-Golgi network (TGN) and endosomal compartments. Two major functions have been attributed to Vpu during HIV-1 replication cycle. Firstly, Vpu targets the newly synthesized CD4 receptor for proteasomal degradation (Willey et al., 1992a). Secondly, it favors the release of viral particles from most human cell types through counteracting the inhibitory effect of BST2 (Neil et al., 2008; Van Damme etal., 2008). More recently, Vpu was shown to down-regulate cell surface expression of two additional mediators of the immune response: the lipid-antigen presenting protein CD1d expressed by antigen-presenting cells (Moll etal., 2010) and the natural killer cells ligand NTB-A (Shah et al., 2010). Vpu appears therefore as a key factor for HIV evasion from the host immune system.

\section{VPU-INDUCED DOWN-REGULATION OF CD4}

$\mathrm{CD} 4$ constitutes the major component of the receptor complex used by primate lentiviruses to infect the cells. It is a $54 \mathrm{kDa}$ 
type I integral glycoprotein expressed at the surface of helper T-lymphocytes, cells of the monocyte/macrophage lineage and hematopoietic progenitor cells.

Infection of $\mathrm{CD}^{+}$cells by primate lentiviruses results in a rapid and constant down-modulation of cell surface CD4 expression level (Ray and Doms, 2006). CD4 down-regulation was proposed to prevent lethal superinfection of cells by additional virions (Wildum et al., 2006), contribute to the escape of infected cells from the immune system and favor viral fitness (Willey et al., 1992b). CD4 depletion in infected cells is achieved by the concerted, though mechanistically distinct, action of three viral proteins: Nef, Vpu and, to a lower extent, Env (Wildum et al., 2006). Nef, produced shortly after infection, enhances internalization of pre-existing CD4 from the cell surface and targets the receptor for lysosomal degradation (Chaudhuri et al., 2007). Env precursor gp160 binds CD4 in the ER and blocks its transport to the cell surface (Crise et al., 1990; Jabbar and Nayak, 1990). $\mathrm{Vpu}$ targets CD4 molecules present in the ER for proteasomal degradation (Willey et al., 1992a).

Vpu induces degradation of newly synthesized CD4 by a multistep process involving binding of Vpu with CD4 via their transmembrane domains (TMD), retention and poly-ubiquitination of CD4 in the ER, followed by its delivery to the ER-associated degradation pathway (ERAD) for further proteasomal degradation (Magadan et al., 2010; Magadan and Bonifacino, 2012; Figure 1). Vpu-induced degradation of CD4 requires the integrity of two phosphoserines $S_{52} / S_{56}$ present in a canonical DSGXXS motif within the cytoplasmic tail of $\mathrm{Vpu}$ and involved in an interaction with the $\beta$-transducin repeat-containing protein 1 or 2 ( $\beta$-TrCP1; $\beta$-TrCP2), two adaptors for the SKP1-cullin1-FBox (SCF) E3 ubiquitin ligase complex (Margottin et al., 1998). Recruitment of the $\mathrm{SCF}^{\mathrm{B}-\mathrm{TrCP}}$ complex by $\mathrm{Vpu}$ results in polyubiquitination of the cytoplasmic tail of CD4 on lysine, serine and threonine residues (Magadan et al., 2010). Interestingly, Vpuinduced SCF-mediated poly-ubiquitination of CD4 contributes to retain the receptor in the ER and enables the recruitment of the ERAD VCP-UFD1L-NPL4 dislocase complex, leading to the extraction of CD4 from the ER membrane and its subsequent degradation by the proteasome (Magadan et al., 2010; Figure 1).

\section{VPU-MEDIATED ANTAGONISM OF THE RESTRICTION FACTOR BST2}

A major breakthrough in understanding how Vpu promotes the release of HIV-1 particles was made by the identification of BST2 as a restriction factor for HIV-1 release (Neil et al., 2008; Van Damme et al., 2008).

\section{CHARACTERISTICS OF BST2}

BST2 is a $30-36 \mathrm{kDa}$ highly glycosylated type II integral membrane protein, constitutively expressed in several cell types and can be up-regulated by type-I interferon and pro-inflammatory stimuli (Neil, 2013). BST2 is composed of a short N-terminal cytoplasmic tail, linked to a transmembrane domain and an extracellular domain anchored to the membrane through a C-terminal glycosylphosphatidylinositol (GPI) moiety (Kupzig et al., 2003). Recently, a short isoform of BST2 produced by an alternative translation initiation from the methionine residue at position 13 has been identified (Cocka and Bates, 2012). BST2 is localized at the plasma membrane (PM) in cholesterol-rich microdomains (rafts) and in intracellular compartments such as the TGN as well as early and recycling endosomes (Kupzig et al., 2003; Masuyama et al., 2009). BST2 was proposed to assemble as a "picket fence" around the lipid rafts, playing a role in organizing membrane microdomains (Billcliff etal., 2013). BST2 was shown to physically trap the de novo formed mature viral particles at the surface of infected cells, thereby considerably reducing virus release (Neil et al., 2008; Van Damme et al., 2008; Perez-Caballero et al., 2009; Hammonds et al., 2010). This activity relies on BST2 ability to form parallel disulfide-bond homo-dimers and to bridge virions and cellular membranes via its $\mathrm{N}-$ and $\mathrm{C}$-terminal membrane anchoring domains (Iwabu et al., 2009; Perez-Caballero et al., 2009; Schubert et al., 2010), with a preference for an "axial" configuration in which the GPI anchors are inserted into virions, and the N-termini transmembrane anchors remain in the infected cells membrane (Venkatesh and Bieniasz, 2013).

Although initially identified as the factor responsible for defective release of HIV-1 mutants lacking the accessory gene $v p u$ (Neil et al., 2008; Van Damme et al., 2008), it is now well established that BST2 restricts the release of nearly all enveloped viruses (retroviruses, herpes viruses, filoviruses, rhabdoviruses, paramyxoviruses, and arenaviruses) (Neil, 2013). BST2 therefore appears as a major mediator of the innate immune defense against viral dissemination. Primates lentiviruses deploy three proteins to antagonize BST2 antiviral activity: Vpu in HIV-1 (Neil et al., 2008; Van Damme et al., 2008); Env in HIV-2 ROD10, HIV-2 RODA, $\mathrm{SIV}_{\mathrm{agm}}$ Tan and $\mathrm{SIV}_{\text {mac239 }} \Delta$ nef isolates (Gupta et al., 2009b; Le Tortorec and Neil, 2009; Hauser et al., 2010; Serra-Moreno et al., 2011) and Nef in most isolates of SIV (Jia et al., 2009; Sauter et al., 2009; Zhang et al., 2009). HIV-1 Vpu, HIV-2 Env, and SIV Nef were shown to down-regulate the cell surface expression level of BST2 to favor its removal from viral budding sites and further viral release (Neil, 2013). To date, the precise mechanism involved in this process has not been fully characterized.

\section{BINDING OF VPU WITH BST2}

Binding of Vpu with BST2 through their respective TMD was shown to be essential to counteract BST2 antiviral activity. Mutagenesis analyzes have unraveled the critical role of residues $\mathrm{I}_{34}$, $\mathrm{L}_{37}, \mathrm{~L}_{41}$ of BST2 and $\mathrm{A}_{14}, \mathrm{~W}_{22}$ and to some extent $\mathrm{A}_{18}$ of $\mathrm{Vpu}$ in this interaction (Vigan and Neil, 2010; Kobayashi et al., 2011). These residues were proposed to form an anti-parallel helix-helix interface (Skasko et al., 2012). Interestingly, recent studies have identified additional residues, located at the periphery of the TMD of BST2 and Vpu respectively, required for the interaction between both proteins and antagonism of BST2 (McNatt et al., 2013; Pickering et al., 2014).

\section{VPU-INDUCED CELL SURFACE DOWN-REGULATION OF BST2}

The mechanism whereby Vpu decreases cell surface BST2 expression appears to rely on interference with BST2 intracellular trafficking. BST2 was thought to cycle between the PM, the TGN and the endosomes, with a fraction sorted for lysosomal degradation through an Endosomal Sorting Complexes Required 


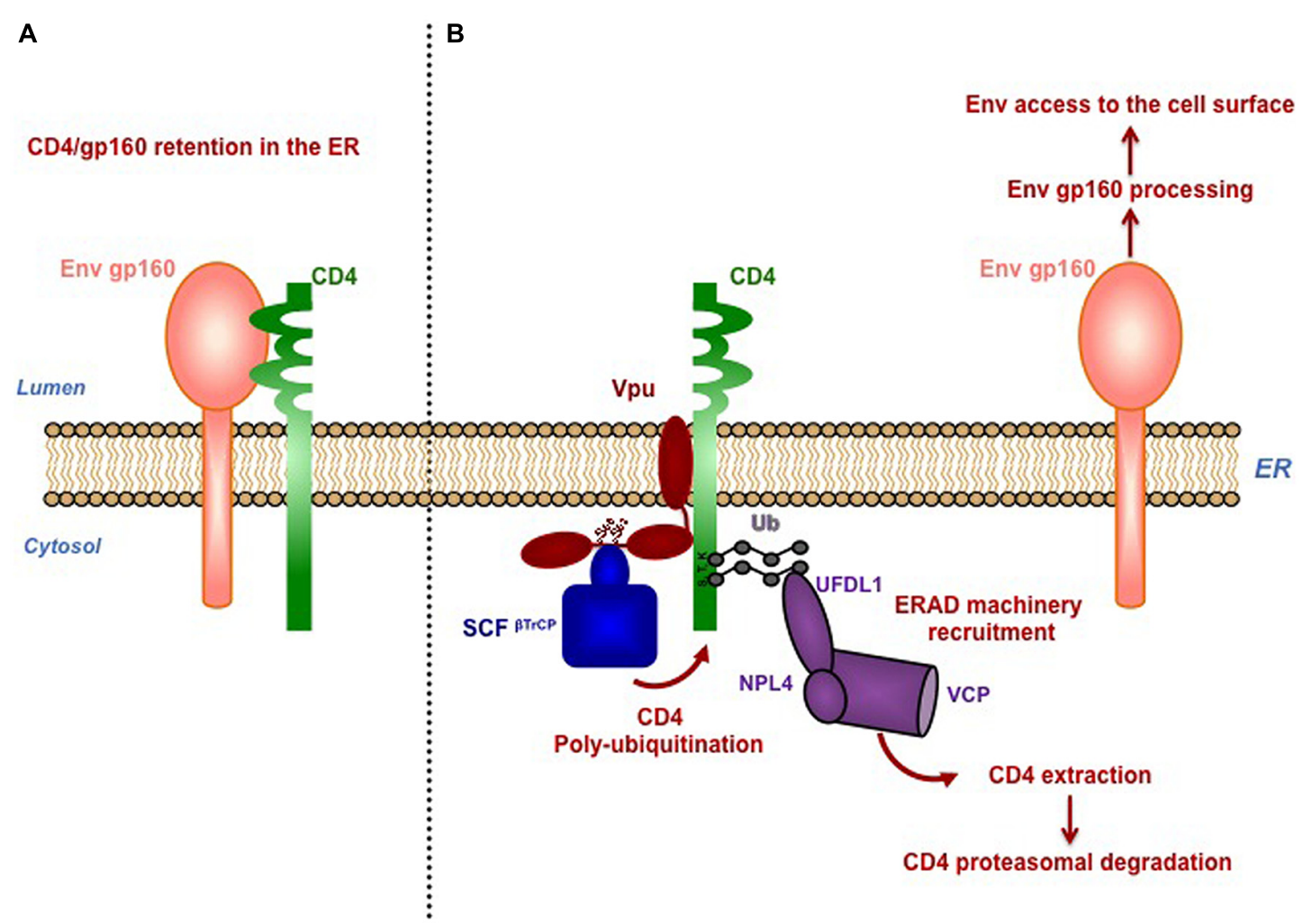

FIGURE 1 | Vpu mediates proteasomal degradation of CD4 to favor viral fitness. (A) Newly synthetized CD4 and HIV-1 envelope precursor gp160 interact in the ER through their luminal domain, preventing Env trafficking to the cell surface. (B) Vpu induces retention of CD4 in the $\mathrm{ER}$ through interaction via their transmembrane region and connects CD4 to SKP1-cullin1-F-Box (SCF) E3 ubiquitin ligase through binding with the SCF subunits $\beta$-TrCP1 and $\beta$-TrCP2. Interaction of $\mathrm{Vpu}$ with $\beta$ - $\operatorname{TrCP}$ involves the conserved phophorylated serines $S_{52}$ and $S_{56}$, located in the cytoplasmic tail of $\mathrm{Vpu}$. Recruitment of the $\mathrm{SCF}^{\circledR-\operatorname{TrCP}}$ complex by $\mathrm{Vpu}$ induces poly-ubiquitination of CD4 on lysine, serine and threonine residues in its cytoplasmic tail. Poly-ubiquitination of CD4 partially contributes its retention in the ER, through a yet-to-be-determined mechanism. Vpu-induced SCF-mediated poly-ubiquitination of CD4 enables the recruitment of the ERAD VCP-UFD1L-NPL4 dislocase complex, leading to the extraction of CD4 from the ER membrane and its subsequent degradation by the proteasome. Degradation of CD4 by Vpu was proposed to dissociate CD4 from newly synthesized viral Env present in the ER, allowing Env maturation and trafficking to the cell surface for its subsequent incorporation in the forming virions. for Transport (ESCRT)-mediated pathway (Rollason et al., 2007; Masuyama etal., 2009; Habermann etal., 2010; Janvier et al., 2011). Internalization of BST2 from the PM occurs through clathrin-coated vesicles, via direct binding of the clathrin adaptor complexes AP2 with non-canonical dual tyrosine residues $\left(\mathrm{Y}_{6} \mathrm{XY}_{8}\right)$ in the cytoplasmic tail of BST2 (Rollason et al., 2007; Masuyama et al., 2009). Binding of BST2 with AP1 complexes regulates its retrieval from the early endosomes back to the TGN (Rollason et al., 2007). Vpu does not increase the rate of BST2 endocytosis but rather slows down the recycling of internalized BST2 back to the PM and inhibits the access of de novo synthetized BST2 to the cell surface, thereby decreasing the resupply of BST2 to the PM (Mitchell et al., 2009; Dube et al., 2011; Lau et al., 2011; Schmidt et al., 2011; Figure 2).

In some cell types such as T-cells and primary macrophages, antagonism of BST2 by $\mathrm{Vpu}$ is not associated with decreased expression of cell surface BST2 (Miyagi et al., 2009; Chu et al., 2012), consistent with the view that Vpu promotes viral release by displacing BST2 from viral budding sites at the PM. Using a sophisticated approach, it has been recently suggested that this function relies on the integrity of a "dileucine"-like motif $\mathrm{E}_{59} \mathrm{VSAL}_{63} \mathrm{~V}$ in the cytoplasmic tail of Vpu (McNatt et al., 2013), first reported to be essential for Vpu to down-regulate CD4 and BST2 expression and counteract BST2 antiviral activity (Hill et al., 2010; Kueck and Neil, 2012). How this motif contributes to these functions is, however unclear. Vpu EXXXLV motif fits the consensus dileucine - based sorting signal (D/E)XXXL(L/I/M) that mediates binding to the AP complexes. However, evidence for an interaction of $\mathrm{Vpu}$ with the AP complexes or a direct contribution of these complexes in Vpu's functions could not be demonstrated (Kueck and Neil, 2012).

\section{VPU-MEDIATED DEGRADATION OF BST2}

In some cell types, Vpu-induced down-regulation of cell surface BST2 is associated with enhanced targeting of the cellular protein to the degradation pathway (Gupta et al., 2009a; Mitchell et al., 2009). This process is ubiquitin-dependent and requires the recruitment of the $\mathrm{SCF}^{\mathrm{B}-\mathrm{TrCP}}$ complex by Vpu via its $\mathrm{DS}_{52} \mathrm{GxxS}_{56}$ motif (Douglas et al., 2009; Goffinet et al., 2009; Mangeat et al., 2009; Mitchell et al., 2009; Tokarev et al., 2010). The importance 


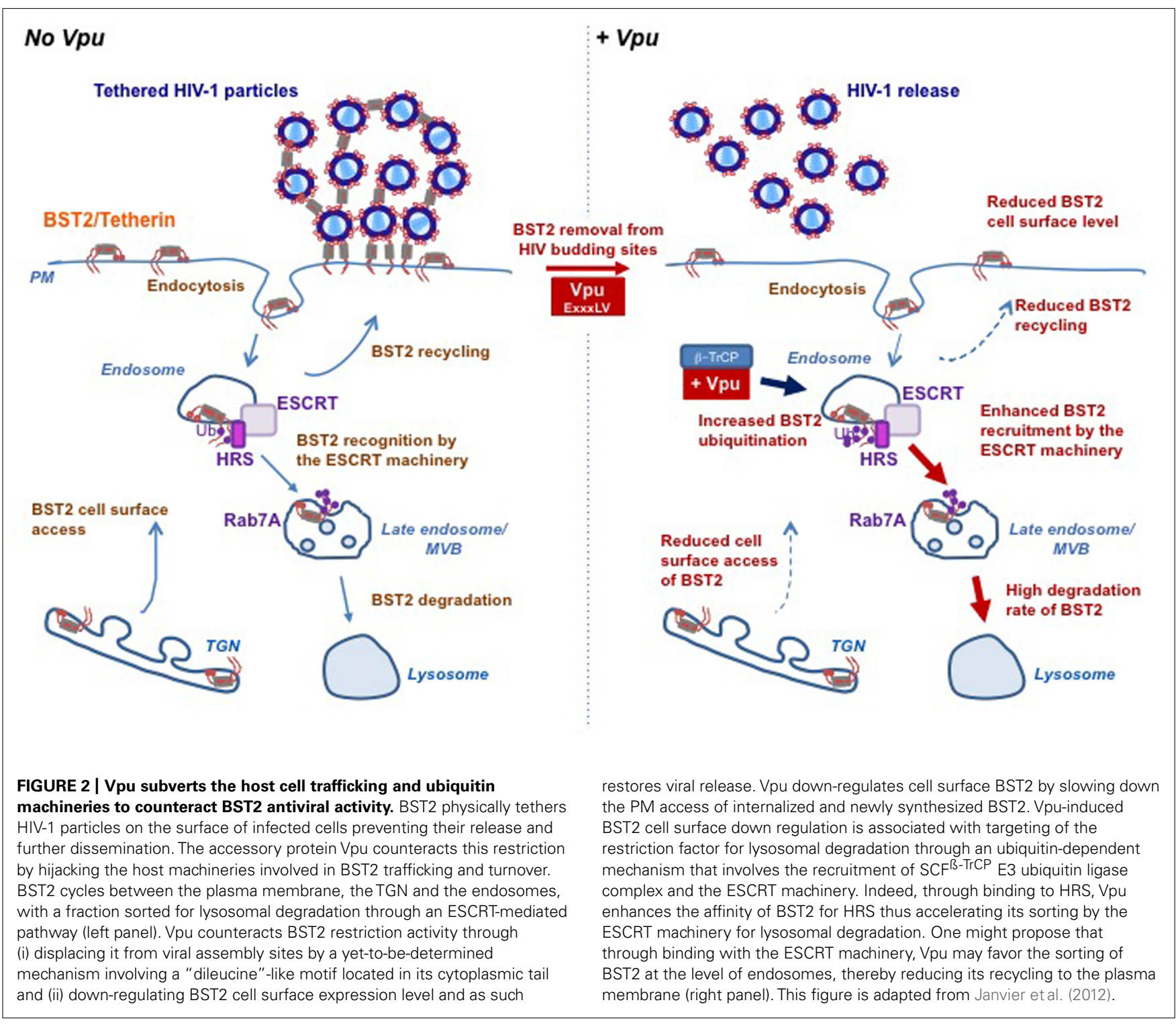

of $\beta$-TrCP in Vpu-mediated antagonism of BST2 antiviral activity remains controversial to date (Douglas et al., 2009; Iwabu et al., 2009; Mangeat et al., 2009; Mitchell et al., 2009; Miyagi et al., 2009; Tervo et al., 2011). BST2 undergoes ubiquitination on lysine residues located in its cytoplasmic tail (Pardieu et al., 2010). Interestingly, Vpu increases BST2 ubiquitination on lysine/serine and threonine residues located in its cytoplasmic tail, as is also observed with CD4 (Tokarev et al., 2010). Mutation of these residues reduces Vpu-induced antagonism of BST2. Consistent with this observation, the short isoform of BST2 lacking these residues shows decreased sensitivity to Vpu antagonism (Tokarev etal., 2010; Cocka and Bates, 2012). One study challenged the requirement of the $\mathrm{S}_{3} \mathrm{~T}_{4} \mathrm{~S}_{5}$ residues in Vpu-induced ubiquitination of BST2 (Gustin et al., 2012) but no explanation has been proposed for this discrepancy.

Despite the similarity in the molecular mechanisms underlying Vpu-induced ubiquitination and degradation of CD4 and BST2,

the fate of both proteins differs. Indeed, it is now well established that Vpu does not target BST2 for proteasomal degradation but induces $\beta$-TrCP-dependent lysosomal sorting of BST2 (Douglas et al., 2009; Iwabu etal., 2009; Mitchell etal., 2009). In agreement with this notion, we highlighted a major role of Rab7, a regulator of the endo/lysosomal trafficking, in this process (Caillet et al., 2011), and revealed that Vpu enhances ESCRT-mediated sorting of BST2 for degradation (Janvier et al., 2011). The ESCRT machinery is a set of four hetero-oligomeric protein complexes involved in the sorting of ubiquitinated membrane proteins into vesicles budding into endosomes for their subsequent degradation in the lysosomes. The ESCRT-0 protein HRS (hepatocyte growth factor-regulated tyrosine kinase substrate) coordinates this process by linking ubiquitinated cargoes and the ESCRT-I component TSG101 (Raiborg and Stenmark, 2009). We showed that Vpu-mediated down-regulation of BST2 and viral release require HRS, and unveiled an increased affinity of BST2 for HRS upon Vpu 
expression (Janvier et al., 2011). One might propose that through binding with HRS and BST2, Vpu accelerates ESCRT-mediated sorting of BST2 to the lysosomes, thereby reducing its recycling to the PM (Janvier et al., 2012; Figure 2). Further evidence of the requirement of the ESCRT machinery in Vpu-mediated BST2 degradation was obtained by the characterization of a new component of the ESCRT-I machinery: the protein UBAP1 (Agromayor et al., 2012). Depletion of UBAP1 abolishes Vpu-induced degradation of BST2, but has no impact on Vpu antagonism of BST2 antiviral activity (Agromayor et al., 2012), consistent with the notion that degradation of BST2 is not strictly required for Vpumediated antagonism of BST2 (Miyagi et al., 2009; Goffinet et al., 2010).

\section{VPU AND BST2 VIRAL SENSING ACTIVITY}

In addition to its activity as a restriction factor of viral release, BST2 has been recently characterized as an innate immune sensor for HIV (Cocka and Bates, 2012; Galao et al., 2012; Tokarev etal., 2013). In 2003, BST2 was first reported to stimulate the activity of the NF- $\kappa \mathrm{B}$ family of transcription factors, using a whole-genome cDNA screen (Matsuda et al., 2003). Recent studies further revealed that tethered HIV particles increase BST2 signaling activity, resulting in enhanced production of proinflammatory stimuli, consistent with a role of BST2 as a sensor for assembled viruses (Cocka and Bates, 2012; Galao et al., 2012; Tokarev et al., 2013). This function seems separable from its activity as an inhibitor of viral release and relies on the integrity of the non-canonical dual tyrosine residues $\left(\mathrm{Y}_{6} \mathrm{XY}_{8}\right)$ regulating its trafficking (Galao et al., 2012; Tokarev et al., 2013). Whether BST2 trafficking is relevant for its signaling activity is unclear. BST2 was proposed to activate the "canonical" NF- $\kappa$ B pathway through engaging mediators of this pathway via its tyrosine motif (Galao et al., 2012; Tokarev et al., 2013). Regulation of this pathway depends on the activation of the transforming growth factor- $\beta$ activated kinase-1 (TAK1)/TAK1-binding protein 1 and 2 (TAB1 and TAB2) complex, through poly-ubiquitination by E3 ligases of the TNF receptor-associated factors (TRAFs) family (Skaug et al., 2009). Interestingly, BST2 was shown to co-immunoprecipitate with TRAF2, TRAF6 as well as the TAK1/TAB1 complex (Galao et al., 2012; Tokarev et al., 2013).

Vpu was shown to counteract BST2 signaling activity through a $\beta$-TrCP-dependent mechanism (Tokarev et al., 2013). Interestingly, over a decade ago, $\mathrm{Vpu}$ was shown to sequester $\beta$-TrCP away from its substrates and inhibit NF- $\kappa \mathrm{B}$ activation by interfering with $\beta$-TrCP-mediated degradation of the NF- $\kappa$ B inhibitor I $\kappa \mathrm{B}$ (Bour et al., 2001; Besnard-Guerin et al., 2004). Whether this mechanism accounts solely for $\mathrm{Vpu}$-induced inhibition of BST2 signaling activity requires further investigation. Furthermore, many questions remain regarding how viral expression triggers BST2 sensing activity.

\section{CONCLUDING REMARKS}

Over the past decade, Vpu has emerged as an important asset for viral egress and evasion from the host antiviral mechanisms. Although tremendous progress has been made toward understanding the mechanisms underlying Vpu's functions, many questions remain regarding how this protein contributes to viral pathogenesis. Vpu's contribution to viral immune evasion relies on its ability to alter the trafficking of its targets by subverting cellular machineries involved this process. However, despite some similarities in the mechanisms involved, major differences have been reported regarding the site of action of $\mathrm{Vpu}$ as well as the fate of its targets in cells. Further characterization of the mechanisms controlling $\mathrm{Vpu}$ expression and distribution in cells as well as the interplay with its targets and the host cell machineries might contribute to explain these pleiotropic effects. In keeping with this line of thought, another fascinating aspect worthy of further investigation is the role of $\mathrm{Vpu}$ with regards to BST2, in cell-to-cell transmission of HIV through virological synapses. So far, conflicting results have been obtained regarding the impact of both proteins on this process, but intriguingly, they have underlined a multifaceted role of BST2 in HIV pathogenesis (Schubert et al., 1995; Gummuluru et al., 2000; Casartelli etal., 2010; Jolly et al., 2010). Adding to this complexity, BST2 was recently described to act as a host sensor of assembled viruses. Therefore, a more detailed characterization of BST2's functions in cells as well as its interplay with $\mathrm{Vpu}$ would contribute to better comprehend the role of both proteins in viral egress and dissemination. Addressing all these questions might provide important insights into AIDS pathogenesis and contribute to the future development of therapeutic strategies.

\section{AUTHOR CONTRIBUTIONS}

Nicolas Roy and Grégory Pacini conceived the figures and contributed to the writing of the manuscript; Clarisse Berlioz-Torrent edited the manuscript; Katy Janvier wrote the manuscript and contributed to the drawing of the figures.

\section{ACKNOWLEDGMENTS}

We sincerely apologize to the authors whose works will not have been cited due to space limitations. We thank Monica Naughtin for critical reading and editing of our manuscript. Nicolas Roy holds a fellowship from ANRS; Grégory Pacini holds a fellowship from the "Ministère Français de l'Enseignement Supérieur et de la Recherche". This work is funded by SIDACTION, the ANR-12JSV3-0005-01 program and by ANRS.

\section{REFERENCES}

Agromayor, M., Soler, N., Caballe, A., Kueck, T., Freund, S. M., Allen, M. D., et al. (2012). The UBAP1 subunit of ESCRT-I interacts with ubiquitin via a SOUBA domain. Structure 20, 414-428. doi: 10.1016/j.str.2011.12.013

Bailes, E., Gao, F., Bibollet-Ruche, F., Courgnaud, V., Peeters, M., Marx, P. A., et al. (2003). Hybrid origin of SIV in chimpanzees. Science 300, 1713. doi: $10.1126 /$ science. 1080657

Besnard-Guerin, C., Belaidouni, N., Lassot, I., Segeral, E., Jobart, A., Marchal, C., et al. (2004). HIV-1 Vpu sequesters beta-transducin repeat-containing protein (betaTrCP) in the cytoplasm and provokes the accumulation of betacatenin and other SCFbetaTrCP substrates. J. Biol. Chem. 279, 788-795. doi: 10.1074/jbc.M308068200

Billcliff, P. G., Rollason, R., Prior, I., Owen, D. M., Gaus, K., and Banting, G. (2013). CD317/tetherin is an organiser of membrane microdomains. J. Cell Sci. 126, 1553-1564. doi: 10.1242/jcs.112953

Bour, S., Perrin, C., Akari, H., and Strebel, K. (2001). The human immunodeficiency virus type $1 \mathrm{Vpu}$ protein inhibits NF-kappa $\mathrm{B}$ activation by interfering with beta TrCP-mediated degradation of Ikappa B. J. Biol. Chem. 276, 15920-15928. doi: 10.1074/jbc.M010533200 
Caillet, M., Janvier, K., Pelchen-Matthews, A., Delcroix-Genete, D., Camus, G., Marsh, M., et al. (2011). Rab7A is required for efficient production of infectious HIV-1. PLoS Pathog. 7:e1002347. doi: 10.1371/journal.ppat.1002347

Casartelli, N., Sourisseau, M., Feldmann, J., Guivel-Benhassine, F., Mallet, A., Marcelin, A. G., et al. (2010). Tetherin restricts productive HIV-1 cellto-cell transmission. PLoS Pathog. 6:e1000955. doi: 10.1371/journal.ppat. 1000955

Chaudhuri, R., Lindwasser, O. W., Smith, W. J., Hurley, J. H., and Bonifacino, J. S. (2007). Downregulation of CD4 by human immunodeficiency virus type 1 Nef is dependent on clathrin and involves direct interaction of Nef with the AP2 clathrin adaptor. J. Virol. 81, 3877-3890. doi: 10.1128/JVI.02725-06

Chu, H., Wang, J. J., Qi, M., Yoon, J. J., Chen, X., Wen, X., et al. (2012). Tetherin/BST-2 is essential for the formation of the intracellular virus-containing compartment in HIV-infected macrophages. Cell Host Microbe 12, 360-372. doi: 10.1016/j.chom.2012.07.011

Cocka, L. J., and Bates, P. (2012). Identification of alternatively translated Tetherin isoforms with differing antiviral and signaling activities. PLoS Pathog. 8:e1002931. doi: 10.1371/journal.ppat.1002931

Courgnaud, V., Formenty, P., Akoua-Koffi, C., Noe, R., Boesch, C., Delaporte, E., et al. (2003). Partial molecular characterization of two simian immunodeficiency viruses (SIV) from African colobids: SIVwrc from Western red colobus (Piliocolobus badius) and SIVolc from olive colobus (Procolobus verus). J. Virol. 77, 744-748. doi: 10.1128/JVI.77.1.744-748.2003

Courgnaud, V., Salemi, M., Pourrut, X., Mpoudi-Ngole, E., Abela, B., Auzel, P., et al. (2002). Characterization of a novel simian immunodeficiency virus with a vpu gene from greater spot-nosed monkeys (Cercopithecus nictitans) provides new insights into simian/human immunodeficiency virus phylogeny. J. Virol. 76, 8298-8309. doi: 10.1128/JVI.76.16.8298-8309.2002

Crise, B., Buonocore, L., and Rose, J. K. (1990). CD4 is retained in the endoplasmic reticulum by the human immunodeficiency virus type 1 glycoprotein precursor. J. Virol. 64, 5585-5593.

Douglas, J. L., Viswanathan, K., McCarroll, M. N., Gustin, J. K., Fruh, K., and Moses, A. V. (2009). Vpu directs the degradation of the human immunodeficiency virus restriction factor BST-2/Tetherin via a $\{$ beta\} TrCP-dependent mechanism. J. Virol. 83, 7931-7947. doi: 10.1128/JVI.00242-09

Dube, M., Paquay, C., Roy, B. B., Bego, M. G., Mercier, J., and Cohen, E. A. (2011). HIV-1 Vpu antagonizes BST-2 by interfering mainly with the trafficking of newly synthesized BST-2 to the cell surface. Traffic 12, 1714-1729. doi: 10.1111/j.16000854.2011.01277.x

Galao, R. P., Le Tortorec, A., Pickering, S., Kueck, T., and Neil, S. J. (2012). Innate sensing of HIV-1 assembly by Tetherin induces NFkappaBdependent proinflammatory responses. Cell Host Microbe 12, 633-644. doi: 10.1016/j.chom.2012.10.007

Gao, F., Bailes, E., Robertson, D. L., Chen, Y., Rodenburg, C. M., Michael, S. F., et al. (1999). Origin of HIV-1 in the chimpanzee Pan troglodytes troglodytes. Nature 397, 436-441. doi: 10.1038/17130

Goffinet, C., Allespach, I., Homann, S., Tervo, H. M., Habermann, A., Rupp, D., et al. (2009). HIV-1 antagonism of CD317 is species specific and involves Vpumediated proteasomal degradation of the restriction factor. Cell Host Microbe 5, 285-297. doi: 10.1016/j.chom.2009.01.009

Goffinet, C., Homann, S., Ambiel, I., Tibroni, N., Rupp, D., Keppler, O. T., et al. (2010). Antagonism of CD317 restriction of human immunodeficiency virus type $1(\mathrm{HIV}-1)$ particle release and depletion of CD317 are separable activities of HIV-1 Vpu. J. Virol. 84, 4089-4094. doi: 10.1128/JVI.01549-09

Gummuluru, S., Kinsey, C. M., and Emerman, M. (2000). An in vitro rapid-turnover assay for human immunodeficiency virus type 1 replication selects for cell-tocell spread of virus. J. Virol. 74, 10882-10891. doi: 10.1128/JVI.74.23.1088210891.2000

Gupta, R. K., Hue, S., Schaller, T., Verschoor, E., Pillay, D., and Towers, G. J. (2009a). Mutation of a single residue renders human tetherin resistant to HIV-1 Vpu-mediated depletion. PLoS Pathog. 5:e1000443. doi: 10.1371/journal.ppat.10 00443

Gupta, R. K., Mlcochova, P., Pelchen-Matthews, A., Petit, S. J., Mattiuzzo, G., Pillay, D., et al. (2009b). Simian immunodeficiency virus envelope glycoprotein counteracts tetherin/BST-2/CD317 by intracellular sequestration. Proc. Natl. Acad. Sci. U.S.A. 106, 20889-20894. doi: 10.1073/pnas.0907075106

Gustin, J. K., Douglas, J. L., Bai, Y., and Moses, A. V. (2012). Ubiquitination of BST-2 protein by HIV-1 Vpu protein does not require lysine, serine, or threonine residues within the BST-2 cytoplasmic domain. J. Biol. Chem. 287, 14837-14850. doi: 10.1074/jbc.M112.349928

Habermann, A., Krijnse-Locker, J., Oberwinkler, H., Eckhardt, M., Homann, S., Andrew, A., et al. (2010). CD317/tetherin is enriched in the HIV-1 envelope and downregulated from the plasma membrane upon virus infection. J. Virol. 84, 4646-4658. doi: 10.1128/JVI.02421-09

Hammonds, J., Wang, J. J., Yi, H., and Spearman, P. (2010). Immunoelectron microscopic evidence for Tetherin/BST2 as the physical bridge between HIV-1 virions and the plasma membrane. PLoS Pathog. 6:e1000749. doi: 10.1371/journal.ppat.1000749

Hauser, H., Lopez, L. A., Yang, S. J., Oldenburg, J. E., Exline, C. M., Guatelli, J. C., et al. (2010). HIV-1 Vpu and HIV-2 Env counteract BST-2/tetherin by sequestration in a perinuclear compartment. Retrovirology 7, 51. doi: 10.1186/1742-46 90-7-51

Hill, M. S., Ruiz, A., Schmitt, K., and Stephens, E. B. (2010). Identification of amino acids within the second alpha helical domain of the human immunodeficiency virus type $1 \mathrm{Vpu}$ that are critical for preventing CD4 cell surface expression. Virology 397, 104-112. doi: 10.1016/j.virol.2009. 10.048

Iwabu, Y., Fujita, H., Kinomoto, M., Kaneko, K., Ishizaka, Y., Tanaka, Y., et al. (2009). HIV-1 accessory protein Vpu internalizes cell-surface BST-2/tetherin through transmembrane interactions leading to lysosomes. J. Biol. Chem. 284, 3506035072. doi: 10.1074/jbc.M109.058305

Jabbar, M. A., and Nayak, D. P. (1990). Intracellular interaction of human immunodeficiency virus type 1 (ARV-2) envelope glycoprotein gp160 with CD4 blocks the movement and maturation of CD4 to the plasma membrane. J. Virol. 64, 6297-6304.

Janvier, K., Pelchen-Matthews, A., Renaud, J. B., Caillet, M., Marsh, M., and Berlioz-Torrent, C. (2011). The ESCRT-0 component HRS is required for HIV-1 Vpu-mediated BST-2/tetherin down-regulation. PLoS Pathog. 7:e1001265. doi: 10.1371/journal.ppat.1001265

Janvier, K., Roy, N., and Berlioz-Torrent, C. (2012). Role of the endosomal ESCRT machinery in HIV-1 Vpu-induced down-regulation of BST2/tetherin. Curr. HIV Res. 10, 315-320. doi: 10.2174/157016212800 792414

Jia, B., Serra-Moreno, R., Neidermyer, W., Rahmberg, A., Mackey, J., Fofana, I. B., etal. (2009). Species-specific activity of SIV Nef and HIV-1 Vpu in overcoming restriction by tetherin/BST2. PLoS Pathog. 5:e1000429. doi: 10.1371/journal.ppat.1000429

Jolly, C., Booth, N. J., and Neil, S. J. (2010). Cell-cell spread of human immunodeficiency virus type- 1 overcomes tetherin/BST-2 mediated restriction in T cells. J. Virol. 84, 12185-12199. doi: 10.1128/JVI.01447-10

Kobayashi, T., Ode, H., Yoshida, T., Sato, K., Gee, P., Yamamoto, S. P., et al. (2011). Identification of amino acids in the human tetherin transmembrane domain responsible for HIV-1 Vpu interaction and susceptibility. J. Virol. 85, 932-945. doi: 10.1128/JVI.01668-10

Kueck, T., and Neil, S. J. (2012). A cytoplasmic tail determinant in HIV-1 Vpu mediates targeting of tetherin for endosomal degradation and counteracts interferon-induced restriction. PLoS Pathog. 8:e1002609. doi: 10.1371/journal.ppat.1002609

Kupzig, S., Korolchuk, V., Rollason, R., Sugden, A., Wilde, A., and Banting, G. (2003). Bst-2/HM1.24 is a raft-associated apical membrane protein with an unusual topology. Traffic 4, 694-709. doi: 10.1034/j.1600-0854.2003. 00129.x

Laguette, N., Sobhian, B., Casartelli, N., Ringeard, M., Chable-Bessia, C., Segeral, E., et al. (2011). SAMHD1 is the dendritic- and myeloid-cell-specific HIV-1 restriction factor counteracted by Vpx. Nature 474, 654-657. doi: 10.1038 /nature 10117

Lau, D., Kwan, W., and Guatelli, J. (2011). Role of the endocytic pathway in the counteraction of BST-2 by human lentiviral pathogens. J. Virol. 85, 9834-9846. doi: 10.1128/JVI.02633-10

Le Tortorec, A., and Neil, S. J. (2009). Antagonism to and intracellular sequestration of human tetherin by the human immunodeficiency virus type 2 envelope glycoprotein. J. Virol. 83, 11966-11978. doi: 10.1128/JVI.01 515-09

Magadan, J. G., and Bonifacino, J. S. (2012). Transmembrane domain determinants of CD4 Downregulation by HIV-1 Vpu. J. Virol. 86, 757-772. doi: 10.1128/JVI.05933-11 
Magadan, J. G., Perez-Victoria, F. J., Sougrat, R., Ye, Y., Strebel, K., and Bonifacino, J. S. (2010). Multilayered mechanism of CD4 downregulation by HIV-1 Vpu involving distinct ER retention and ERAD targeting steps. PLoS Pathog. 6:e1000869. doi: 10.1371/journal.ppat.1000869

Maldarelli, F., Chen, M. Y., Willey, R. L., and Strebel, K. (1993). Human immunodeficiency virus type $1 \mathrm{Vpu}$ protein is an oligomeric type I integral membrane protein. J. Virol. 67, 5056-5061.

Malim, M. H., and Bieniasz, P. D. (2012). HIV Restriction factors and mechanisms of evasion. Cold Spring Harb. Perspect. Med. 2:a006940. doi: 10.1101/cshperspect.a006940

Malim, M. H., and Emerman, M. (2008). HIV-1 accessory proteins-ensuring viral survival in a hostile environment. Cell Host Microbe 3, 388-398. doi: 10.1016/j.chom.2008.04.008

Mangeat, B., Gers-Huber, G., Lehmann, M., Zufferey, M., Luban, J., and Piguet, V. (2009). HIV-1 Vpu neutralizes the antiviral factor Tetherin/BST-2 by binding it and directing its beta-TrCP2-dependent degradation. PLoS Pathog. 5:e1000574. doi: 10.1371/journal.ppat.1000574

Margottin, F., Bour, S. P., Durand, H., Selig, L., Benichou, S., Richard, V., et al. (1998). A novel human WD protein, h-beta TrCp, that interacts with HIV-1 Vpu connects CD4 to the ER degradation pathway through an F-box motif. Mol. Cell 1, 565-574. doi: 10.1016/S1097-2765(00)80056-8

Masuyama, N., Kuronita, T., Tanaka, R., Muto, T., Hirota, Y., Takigawa, A., et al. (2009). HM1.24 is internalized from lipid rafts by clathrin-mediated endocytosis through interaction with alpha-adaptin. J. Biol. Chem. 284, 15927-15941. doi: 10.1074/jbc.M109.005124

Matsuda, A., Suzuki, Y., Honda, G., Muramatsu, S., Matsuzaki, O., Nagano, Y., et al. (2003). Large-scale identification and characterization of human genes that activate NF-kappaB and MAPK signaling pathways. Oncogene 22, 3307-3318. doi: 10.1038/sj.onc.1206406

McNatt, M. W., Zang, T., and Bieniasz, P. D. (2013). Vpu binds directly to tetherin and displaces it from nascent virions. PLoS Pathog. 9:e1003299. doi: 10.1371/journal.ppat.1003299

Mitchell, R. S., Katsura, C., Skasko, M. A., Fitzpatrick, K., Lau, D., Ruiz, A., et al. (2009). Vpu antagonizes BST-2-mediated restriction of HIV-1 release via beta-TrCP and endo-lysosomal trafficking. PLoS Pathog. 5:e1000450. doi 10.1371/journal.ppat.1000450

Miyagi, E., Andrew, A. J., Kao, S., and Strebel, K. (2009). Vpu enhances HIV1 virus release in the absence of Bst-2 cell surface down-modulation and intracellular depletion. Proc. Natl. Acad. Sci. U.S.A. 106, 2868-2873. doi: 10.1073/pnas.0813223106

Moll, M., Andersson, S. K., Smed-Sorensen, A., and Sandberg, J. K. (2010). Inhibition of lipid antigen presentation in dendritic cells by HIV-1 Vpu interference with CD1d recycling from endosomal compartments. Blood 116, 1876-1884. doi: 10.1182/blood-2009-09-243667

Neil, S. J. (2013). The antiviral activities of tetherin. Curr. Top. Microbiol. Immunol. 371, 67-104. doi: 10.1007/978-3-642-37765-5_3

Neil, S. J., Zang, T., and Bieniasz, P. D. (2008). Tetherin inhibits retrovirus release and is antagonized by HIV-1 Vpu. Nature 451, 425-430. doi: 10.1038/nature 06553

Pardieu, C., Vigan, R., Wilson, S. J., Calvi, A., Zang, T., Bieniasz, P., et al. (2010). The RING-CH ligase K5 antagonizes restriction of KSHV and HIV-1 particle release by mediating ubiquitin-dependent endosomal degradation of tetherin. PLoS Pathog. 6:e1000843. doi: 10.1371/journal.ppat.10 00843

Perez-Caballero, D., Zang, T., Ebrahimi, A., McNatt, M. W., Gregory, D. A., Johnson, M. C., etal. (2009). Tetherin inhibits HIV-1 release by directly tethering virions to cells. Cell 139, 499-511. doi: 10.1016/j.cell.2009. 08.039

Pickering, S., Hue, S., Kim, E. Y., Reddy, S., Wolinsky, S. M., and Neil, S. J. (2014). Preservation of tetherin and CD4 counter-activities in circulating Vpu alleles despite extensive sequence variation within HIV-1 infected individuals. PLoS Pathog. 10:e1003895. doi: 10.1371/journal.ppat.1003895

Raiborg, C., and Stenmark, H. (2009). The ESCRT machinery in endosomal sorting of ubiquitylated membrane proteins. Nature 458, 445-452. doi 10.1038/nature07961

Ray, N., and Doms, R. W. (2006). HIV-1 coreceptors and their inhibitors Curr. Top. Microbiol. Immunol. 303, 97-120. doi: 10.1007/978-3-540-333 97-5_5
Rollason, R., Korolchuk, V., Hamilton, C., Schu, P., and Banting, G. (2007) Clathrin-mediated endocytosis of a lipid-raft-associated protein is mediated through a dual tyrosine motif. J. Cell Sci. 120, 3850-3858. doi: 10.1242/jcs. 003343

Sauter, D., Schindler, M., Specht, A., Landford, W. N., Munch, J., Kim, K. A., et al. (2009). Tetherin-driven adaptation of Vpu and Nef function and the evolution of pandemic and non-pandemic HIV-1 strains. Cell Host Microbe 6, 409-421. doi: 10.1016/j.chom.2009.10.004

Schmidt, S., Fritz, J. V., Bitzegeio, J., Fackler, O. T., and Keppler, O. T. (2011). HIV-1 $\mathrm{Vpu}$ blocks recycling and biosynthetic transport of the intrinsic immunity factor CD317/tetherin to overcome the virion release restriction. MBio 2, e00036-00011. doi: 10.1128/mBio.00036-11

Schubert, H. L., Zhai, Q., Sandrin, V., Eckert, D. M., Garcia-Maya, M., Saul, L., etal. (2010). Structural and functional studies on the extracellular domain of BST2/tetherin in reduced and oxidized conformations. Proc. Natl. Acad. Sci. U.S.A. 107, 17951-17956. doi: 10.1073/pnas.1008 206107

Schubert, U., Clouse, K. A., and Strebel, K. (1995). Augmentation of virus secretion by the human immunodeficiency virus type $1 \mathrm{Vpu}$ protein is cell type independent and occurs in cultured human primary macrophages and lymphocytes. J. Virol. 69, 7699-7711.

Serra-Moreno, R., Jia, B., Breed, M., Alvarez, X., and Evans, D. T. (2011). Compensatory changes in the cytoplasmic tail of gp41 confer resistance to tetherin/BST-2 in a pathogenic nef-deleted SIV. Cell Host Microbe 9, 46-57. doi: 10.1016/j.chom.2010.12.005

Shah, A. H., Sowrirajan, B., Davis, Z. B., Ward, J. P., Campbell, E. M., Planelles, V., etal. (2010). Degranulation of natural killer cells following interaction with HIV-1-infected cells is hindered by downmodulation of NTB-A by Vpu. Cell Host Microbe 8, 397-409. doi: 10.1016/j.chom.2010. 10.008

Sheehy, A. M., Gaddis, N. C., Choi, J. D., and Malim, M. H. (2002). Isolation of a human gene that inhibits HIV-1 infection and is suppressed by the viral Vif protein. Nature 418, 646-650. doi: 10.1038/nature 00939

Skasko, M., Wang, Y., Tian, Y., Tokarev, A., Munguia, J., Ruiz, A., et al. (2012). HIV$1 \mathrm{Vpu}$ protein antagonizes innate restriction factor BST-2 via lipid-embedded helix-helix interactions. J. Biol. Chem. 287, 58-67. doi: 10.1074/jbc.M111. 296772

Skaug, B., Jiang, X., and Chen, Z. J. (2009). The role of ubiquitin in NF-kappaB regulatory pathways. Annu. Rev. Biochem. 78, 769-796. doi: 10.1146/annurev.biochem.78.070907.102750

Strebel, K., Klimkait, T., and Martin, M. A. (1988). A novel gene of HIV-1, vpu, and its 16-kilodalton product. Science 241, 1221-1223. doi: 10.1126/science.32 61888

Stremlau, M., Owens, C. M., Perron, M. J., Kiessling, M., Autissier, P., and Sodroski, J. (2004). The cytoplasmic body component TRIM5alpha restricts HIV1 infection in old world monkeys. Nature 427, 848-853. doi: 10.1038/nature 02343

Tervo, H. M., Homann, S., Ambiel, I., Fritz, J. V., Fackler, O. T., and Keppler, O. T. (2011). Beta-TrCP is dispensable for Vpu's ability to overcome the CD317/Tetherin-imposed restriction to HIV-1 release. Retrovirology 8, 9. doi: 10.1186/1742-4690-8-9

Tokarev, A., Suarez, M., Kwan, W., Fitzpatrick, K., Singh, R., and Guatelli, J. (2013). Stimulation of NF-kappaB activity by the HIV restriction factor BST2. J. Virol. 87, 2046-2057. doi: 10.1128/JVI. 02272-12

Tokarev, A. A., Munguia, J., and Guatelli, J. C. (2010). Serine-threonine ubiquitination mediates downregulation of BST-2/tetherin and relief of restricted virion release by HIV-1 Vpu. J. Virol. 85, 51-63. doi: 10.1128/JVI.01 795-10

Van Damme, N., Goff, D., Katsura, C., Jorgenson, R. L., Mitchell, R., Johnson, M. C., et al. (2008). The interferon-induced protein BST-2 restricts HIV-1 release and is downregulated from the cell surface by the viral Vpu protein. Cell Host Microbe 3, 245-252. doi: 10.1016/j.chom.2008 03.001

Venkatesh, S., and Bieniasz, P. D. (2013). Mechanism of HIV-1 virion entrapment by tetherin. PLoS Pathog. 9:e1003483. doi: 10.1371/journal.ppat.10 03483 
Vigan, R., and Neil, S. J. (2010). Determinants of tetherin antagonism in the transmembrane domain of the human immunodeficiency virus type-1 (Hiv-1) Vpu protein. J. Virol. 84, 12958-12970. doi: 10.1128/JVI.01699-10

Wildum, S., Schindler, M., Munch, J., and Kirchhoff, F. (2006). Contribution of $\mathrm{Vpu}$, Env, and Nef to CD4 down-modulation and resistance of human immunodeficiency virus type 1-infected T cells to superinfection. J. Virol. 80, 8047-8059. doi: 10.1128/JVI.00252-06

Willey, R. L., Maldarelli, F., Martin, M. A., and Strebel, K. (1992a). Human immunodeficiency virus type $1 \mathrm{Vpu}$ protein induces rapid degradation of CD4. J. Virol. 66, 7193-7200.

Willey, R. L., Maldarelli, F., Martin, M. A., and Strebel, K. (1992b). Human immunodeficiency virus type $1 \mathrm{Vpu}$ protein regulates the formation of intracellular gp160-CD4 complexes. J. Virol. 66, 226-234.

Zhang, F., Wilson, S. J., Landford, W. C., Virgen, B., Gregory, D., Johnson, M. C., et al. (2009). Nef proteins from simian immunodeficiency viruses are tetherin antagonists. Cell Host Microbe 6, 54-67. doi: 10.1016/j.chom.2009.05.008
Conflict of Interest Statement: The authors declare that the research was conducted in the absence of any commercial or financial relationships that could be construed as a potential conflict of interest.

Received: 09 February 2014; accepted: 31 March 2014; published online: 01 May 2014. Citation: Roy N, Pacini G, Berlioz-Torrent C and Janvier K (2014) Mechanisms underlying HIV-1 Vpu-mediated viral egress. Front. Microbiol. 5:177. doi: $10.3389 /$ fmicb.2014.00177

This article was submitted to Virology, a section of the journal Frontiers in Microbiology. Copyright (c) 2014 Roy, Pacini, Berlioz-Torrent and Janvier. This is an open-access article distributed under the terms of the Creative Commons Attribution License (CC BY). The use, distribution or reproduction in other forums is permitted, provided the original author(s) or licensor are credited and that the original publication in this journal is cited, in accordance with accepted academic practice. No use, distribution or reproduction is permitted which does not comply with these terms. 